\title{
Symposium review: Late-gestation maternal factors affecting the health and development of dairy calves*
}

\section{Angel Abuelo† ${ }^{\circ}$}

Department of Large Animal Clinical Sciences, College of Veterinary Medicine, Michigan State University, 736 Wilson Rd., East Lansing 48824

\section{ABSTRACT}

Efficient production of heifers is fundamental to the productivity and sustainability of dairy farms. However, high preweaning morbidity and mortality rates are frequently reported worldwide, imposing substantial welfare and economic implications. A major contributing factor to disease susceptibility in the neonatal stage is the inability of calves to mount an effective immune response. Appreciation is now greater that exposure in utero to several stresses (nutritional, social, metabolic, and so on) during the last stages of pregnancy have downstream carryover effects in calves' health, growth, and development. Suboptimal intrauterine conditions during critical periods of development lead to changes in tissue structure and function that may have long-term consequences on the offspring's physiology and disease susceptibility. Indeed, preweaning metabolic function and growth are associated with future milk production. Thus, late-gestation carryover effects span into the lactating stage of the heifers. Nevertheless, researchers have been studying how to minimize these effects. This review will discuss the effects of maternal stress during late gestation on the offspring's growth, productivity, metabolism, and health. In addition, strategies focusing on maternal interventions that improve neonatal health will be discussed. A better understanding of the intrauterine conditions affecting calf health and growth may facilitate the design of management practices that could improve neonatal development and future cow productivity.

Key words: dairy calf, periparturient cow, transition period, immunity, developmental programming

Received July 16, 2019.

Accepted December 3, 2019.

*Presented as part of the Growth and Development Symposium: Maternal Factors that Influence the Neonate: An Update on Fetal Programming at the ADSA Annual Meeting, Cincinnati, Ohio, June 2019.

†Corresponding author: abuelo@msu.edu

\section{INTRODUCTION}

The efficient rearing of replacement stock is essential for guaranteeing the sustainability of dairy farms and optimizing milk production. Diseases during the neonatal stage, however, significantly affect the economic viability of dairy operations, due to the costs associated with calf losses, treatments, and long-term effects on performance. Calf preweaning morbidity and mortality risks have been reported to be high (about $23-35 \%$ morbidity and $3.5-10.5 \%$ mortality) in several countries, including the United States, Canada, and Australia (NAHMS, 2014; Windeyer et al., 2014; Abuelo et al., 2019a). Infectious diseases such as diarrhea or pneumonia are responsible for the majority of preweaned calf deaths at 56.5 and $22.5 \%$, respectively (NAHMS, 2007). The economic loss associated with calf mortality in Norway, where calf production is 280,000 heads per year, was estimated to be approximately $\$ 10$ million in 2006 (Østerås et al., 2007).

A major contributing factor to this high disease incidence in the neonatal stage is the inability of calves to mount an effective immune response (Chase et al., 2008). Calves are born with a naïve and immature immune system, relying on transfer of passive immunity (primarily antibodies) for protection against pathogens (Godden et al., 2019). The calf's immune system, however, starts developing in utero as early as $42 \mathrm{~d}$ of gestation (Schultz et al., 1973) and can, therefore, be affected by maternal conditions during pregnancy. Moreover, the immune system is expected to have lower priority in fetal nutrient partitioning than other systems (Wu et al., 2006). Therefore, the immune system and, subsequently, the animal's ability to fight infectious diseases are some of the first affected systems when supply of nutrients to the fetus is limited.

Developmental programming, also referred to as fetal programming, refers to the concept that factors affecting fetal growth and development cause longterm changes in tissue structure, function, or both (Wu et al., 2006). This concept was first established using epidemiologic studies to show a strong association between adverse phenotypical characteristics (e.g., 
metabolic syndrome, growth alterations, and immune and reproductive dysfunction) and in utero exposure to various stressors (Barker, 2007). Subsequently, it has been shown in humans and livestock studies that every organ system and metabolic function can be affected by developmental programming (Reynolds et al., 2010).

In developmental programming, the timing and duration of insults or stressors will influence the observed effect, depending on which tissue or organs are developing at the time (Reynolds et al., 2010). Hence, different critical points or windows of susceptibility to stressors exist during developmental programming throughout gestation: the peri-conception period and early, mid, and late gestation. Because of its focus on health and growth, this article will focus only on developmental programming during late gestation, given that it is the period of greatest fetal growth and fastest proliferation of immune cells in the bovine fetus (Higgins et al., 1983). Adipogenesis is another process that, although initiated in mid gestation, takes place to a greater extent in late gestation (Feve, 2005) and is susceptible to developmental programming (Du et al., 2010). It is important to highlight, however, that what occurred in previous pregnancy stages will also influence lategestational effects. For example, the number of myocytes in muscle fiber is established in mid gestation, and late-gestational insults will affect myocyte size and intramuscular adipocyte formation but not change the number of myocytes in muscle fibers (Du et al., 2010). Similarly, liver mass is set during early pregnancy under the control of many genes that are sensitive to nutritional and hormonal regulation in utero, whereas the regulation of liver maturation takes place during late gestation (Hyatt et al., 2008). Therefore, variations in the availability of nutrients to the fetus can result in long-lasting changes in the structure and function of key fetal tissues related to metabolism, growth, and health.

This review will discuss the effects of maternal nutritional and metabolic factors during late gestation on the offspring's growth, productivity, metabolism, and health, including interventions in the dam that result in improved neonatal health. Other factors known to influence fetal programming in cattle are beyond the scope of this review. For example, the readers are directed to other recent reviews summarizing the effects of late-gestational heat stress on the offspring (Dahl et al., 2016; Tao et al., 2019).

\section{OVERVIEW OF DEVELOPMENTAL PROGRAMMING}

Exposure of the fetus to different insults during critical periods of development may lead to adaptations that prove to be detrimental and associated with adult defects in several organ systems. In humans, it is recognized that a wide range of gestational events can alter the fetal developmental trajectory. These include, among others, maternal nutritional deficit or excess, disease states, environmental conditions, and exposure to toxicants (Padmanabhan et al., 2016), all of which are also relevant in dairy cattle.

Developmental programming takes place through various mechanisms. It is outside the scope of this article to provide an in-depth review of all these factors. Depending on the type of insult, organ system affected, and the developmental window in which the insult occurs, several mechanisms have been proposed linking these insults to unfavorable outcomes such as lower survivability. Nonetheless, different insults can lead to offspring responses that converge on common mechanistic pathways, culminating in the development of similar adult outcomes (Padmanabhan et al., 2016).

One of these mechanisms is through changes in the placenta. After implantation, the placenta controls the exchange of substances between the dam and the fetus, and any factor capable of affecting the placenta can lead to altered fetal growth and organ development (Reynolds et al., 2010), including, among others, blood flow to the placenta and transporter changes that ultimately change placental permeability and function. In cases of undernutrition, the transport of nutrients to the fetus can be reduced and vice versa in cases of overnutrition, resulting in changes in the availability of nutrients (e.g., glucose, fatty acids, AA) to the fetus that ultimately can affect the growth and development of fetal tissues (Gaccioli et al., 2013).

In addition to changes in placental function, altered growth and development of fetal tissues can lead to irreversible changes in tissue and organ structure as well as permanent changes in tissue function (e.g., gene expression). An example of changes in function due to alterations in gene expression are the epigenetic alterations. These are transgenerational heritable changes in gene expression without alteration of the genetic code. Epigenetic alterations, such as DNA methylation, histone modification, chromatin packing, and microRNA expression, determine whether a particular gene is available for transcription or not. Ample evidence exists of several maternal factors affecting the fetal epigenome, including nutrition and metabolic status, toxicants (e.g., pesticides or herbicides), social interactions, and environmental stressors such as heat (Skibiel et al., 2018; Reynolds et al., 2019).

Another mechanism believed to be involved in prenatal programming is oxidative stress (OS), a deleterious process that results in damage of cell components, such as lipids, proteins, and DNA. However, it is unknown whether the developmental programming of OS may be 
through directly modulating gene expression or indirectly through the effects of certain oxidized molecules (Luo et al., 2006).

\section{EFFECT OF MATERNAL NUTRITION}

Maternal nutritional status during pregnancy is a major factor in developmental programming events and ultimately offspring outcomes (Reynolds and Caton, 2012). Maternal nutrition can alter the fetal and postnatal epigenome and transcriptome, often leading to measurable alterations in metabolism and growth (Elolimy et al., 2019). Also, placental function is altered to match fetal growth to the ability of the maternal supply line (nutrient restriction or excess) to allocate resources to the fetus, thereby resulting in changes of nutrients available to the fetus and affecting fetal growth and the long-term health of the offspring (Gaccioli et al., 2013).

\section{Maternal Undernutrition}

Most developmental programming research in ruminants has focused on nutrient restriction in pregnant animals (Chavatte-Palmer et al., 2015). In cattle, probably the best examples of the effect of maternal undernutrition are birth defects in calves that are associated with deficiencies in nutrients in the dam during pregnancy, such as chondrodystrophy in calves associated with manganese deficiency (Valero et al., 1990). However, maternal nutrient supply below requirements is also associated with decreased pre- and postnatal growth, altered immune responses, and increased morbidity and mortality risks not only during the neonatal stage but also during the productive life of cows (Cooke, 2019). For example, Moriel et al. (2016) reported that restricting energy supply of beef cows to $70 \%$ of daily $\mathrm{NE}_{\mathrm{M}}$ requirements during the last $40 \mathrm{~d}$ of gestation resulted in calves that had lower titers after bovine diarrhea virus vaccination at $306 \mathrm{~d}$ of life. Hence, even short-term restrictions have long-term implications; calves born to cows fed the restricted diet showed decreased humoral responses to vaccination 10 mo after birth (Moriel et al., 2016).

In dairy cows, survival to second parity and milk yield were reduced, and SCC was increased, in the offspring of dams with greater milk yield before conception and during gestation (Berry et al., 2008). In dairy farms, cows are pregnant and lactating for most of the pregnancy, meaning that the fetus competes for nutrients with the requirements for milk production - with cows producing more milk likely providing less nutrients to the fetus. Heifers born to dams that were lactating while pregnant produced $53 \mathrm{~kg}$ less milk, lived $16 \mathrm{~d}$ less, and were metabolically less efficient than those born to dams that were not lactating during pregnancy (Gonzalez-Recio et al., 2012). Furthermore, the reduced milk production, survivability, and metabolic efficiency of the offspring were increased according to the cow level of milk production. Thus, calves born to the more productive cows can be precluded from fully expressing their genetic merit. Despite these potential effects on the offspring, maintaining tight calving intervals is critical to ensuring the economic efficiency of the dairy farm (Dalcq et al., 2018). Hence, ensuring adequate nutrition of lactating pregnant cows is critical to avoid the negative effects of reduced nutrient availability during pregnancy on the health and productivity of offspring. Fortunately, in most modern dairy farms, dry cows are fed a TMR diet designed to meet the dietary requirements. However, it is important to consider that other housing, social, and environmental factors that might affect feed intake could potentially affect fetal development. For example, management factors such as overstocking, inadequate heat abatement, or health status (e.g., lameness) that result in decreased feed intake in the late dry period will not only affect the cow in early lactation but also potentially have a negative effect on the offspring development.

\section{Maternal Overnutrition}

In commercial dairy farms, it is arguably more common nowadays to find overconditioned cows at dry-off than underconditioned, as has been shown in some farms (Chebel et al., 2018). In humans, maternal obesity has been linked to increased adiposity and metabolic syndrome (i.e., type 2 diabetes, high blood pressure, and so on) in the offspring (Alfaradhi and Ozanne, 2011). Maternal obesity upregulated the expression of genes related to lipogenesis and adipogenesis in the adipose tissue of rats (Borengasser et al., 2011). Metabolic syndrome in humans has many similarities with fat cow syndrome (De Koster and Opsomer, 2012), and therefore, it is likely that similar links between overconditioned pregnant cows and increased risk of metabolic disease in the offspring also exist in dairy cows (Opsomer et al., 2016). The effect of maternal overnutrition in fetal programming in cattle has not been as extensively studied as undernutrition. Nevertheless, there is evidence of its existence in beef cattle, where maternal overnutrition during gestation resulted in increased mRNA expression of intramuscular adipogenesis and collagen deposition in skeletal muscle (Duarte et al., 2014). Therefore, late gestation overnutrition plausibly affects tissue structure in dairy calves. Dairy cows with high BCS at dry-off are more likely to lose BCS during late gestation, whereas cows with low BCS at dry-off will likely gain BCS in the dry period (Chebel 
et al., 2018). Changes in body composition during late gestation can potentially negatively affect the calf's development (discussed later in the Effect of Maternal Metabolic Status section). However, further research is needed to elucidate and quantify the effect of maternal overnutrition and adiposity during gestation on dairy calf growth and health outcomes.

\section{DCAD Diets}

Dairy cows are usually fed a negative DCAD diet during the last weeks of gestation as a strategy to prevent clinical hypocalcemia (Lean et al., 2006). In fact, a recent meta-analysis revealed that feeding a negative DCAD resulted in decreased risks of clinical hypocalcemia, retained placenta, metritis, and overall disease during the early postpartum period (Lean et al., 2019). Diets with a negative DCAD aim to create a compensated metabolic acidosis in the cows, which decreases their blood $\mathrm{pH}$ and activates different homeostatic mechanisms that result in increased mobilization and absorption of Ca (Goff, 2006). However, it is possible that this maternal metabolic acidosis induced by negative DCAD prepartum diets could also acidify the calves' blood in utero, because of the highly vascularized nutrient transfer system that occurs during the last trimester (Collazos et al., 2017). Metabolic and respiratory acidosis in newborn calves has been associated with reduced efficiency of colostral Ig absorption, leading to increased risk of mortality in dairy calves (Besser and Gay, 1994). Hence, it was initially hypothesized that feeding a negative DCAD to dams could have negative downstream implications for postnatal calf health and development.

Some early studies reported decreased IgG absorption in calves born to dams fed acidogenic diets (Quigley and Drewry, 1998). However, contradictory results were found in more recent controlled studies. For example, the efficiency of $\mathrm{IgG}$ absorption and the concentrations of Ig were similar between calves whose dams received a diet with a DCAD of $-100 \mathrm{mEq} / \mathrm{kg}$ and those born to dams fed a DCAD of $+77 \mathrm{mEq} / \mathrm{kg}$ during the last $21 \mathrm{~d}$ prepartum (Morrill et al., 2010). Collazos et al. (2017) also found no effect of the level of negative DCAD $(-70$ or $-180 \mathrm{mEq} / \mathrm{kg}$ ) or feeding duration (last 21 or $42 \mathrm{~d}$ prepartum) on IgG efficiency of absorption and serum concentrations. However, a more evident metabolic acidosis was identified at birth in the calves born to dams fed the $-70 \mathrm{mEq} / \mathrm{kg}$ DCAD diet, although differences in acid-base status were not present at $3 \mathrm{~d}$ of life and no associations existed between measures of metabolic acidosis and efficiency of IgG absorption. Tucker et al. (1992) also reported that the DCAD level of the diet $(-30$ or $+90 \mathrm{mEq} / \mathrm{kg})$ did not affect the acid-base status or the plasma mineral content of their calves. Similar results were recently confirmed, where feeding an acidogenic diet to cows prepartum did not alter blood mineral or gas concentrations in their calves compared with calves born to dams fed a nonacidified diet (Diehl et al., 2018). In addition, the level of negative DCAD was not associated with differences in calf $\mathrm{BW}$ at birth or ADG up to $62 \mathrm{~d}$ of age; however, heifers born to dams fed a DCAD diet during the last $42 \mathrm{~d}$ prepartum had lower BW at birth and $62 \mathrm{~d}$ of life compared with calves born to dams fed the last 21 d prepartum (Collazos et al., 2017). This difference, however, was not present at 3 and 6 mo of age, indicating that the differences in birth BW were compensated during the first months of life. The study of Collazos et al. (2017) is the only one, to the author's knowledge, that also examined calf morbidity across maternal treatments, not finding any statistical difference in the percentage of calves treated for diarrhea. Collectively, these data indicate that the changes in acid-base balance observed at birth in calves whose dams received a negative DCAD diet prepartum are transient in nature and do not affect passive transfer of immunity, disease risk, or growth.

\section{Colostrum Composition and Volume}

In addition to in utero effects, nutrition during late pregnancy can also affect calves' development and immunity through changes in colostrum production. Colostrum intake is critical not only for transfer of passive immunity and disease resistance but also for other long-term implications such as improved feed efficiency, reduced age at first calving, and higher milk production in the first lactations (Jones et al., 2004; Faber et al., 2005; Godden, 2008; Godden et al., 2019). Colostrogenesis takes place during the last several weeks prepartum (Brandon et al., 1971) and therefore is conditioned by the dam's status during this time.

Several factors affect the colostrum concentration of Ig, including, among others, dry period length, time from calving to milking, dam's vaccination status, parity, late-gestation nutrition, and season of calving (Godden, 2008). An in-depth review of all the factors associated with colostral Ig concentration is beyond the scope of this article. Nevertheless, it is important to highlight how maternal nutrition might influence calf development and immunity through changes in colostrum composition. Approximately $19.7 \%$ of calves in the United States receive pooled colostrum (Urie et al., 2018), which can potentially compensate for individual cows producing insufficient or low-quality colostrum. 
However, herd-level factors influencing colostrum composition are still relevant.

Concentration of $\mathrm{CP}$ in the dry diet has not been associated with the IgG concentration of colostrum (Blecha et al., 1981; Quigley and Drewry, 1998). Conversely, the absorption of IgG was reduced by $21.8 \%$ in calves that received colostrum obtained from cows fed restricted amounts of energy and CP (Hough et al., 1990). On the other hand, compared with cows that received a dry period diet formulated to meet energy requirements, those receiving a high energy diet had lower colostral IgG concentrations, higher concentrations of insulin, and increased colostrum concentration of de novo fatty acids (Mann et al., 2016). This study also showed that changes in colostrum composition beyond $\operatorname{IgG}$ concentration, such as insulin and fatty acids, are achievable through dietary interventions. The provision of hormones and growth factors through colostrum affect the maturation of the neonatal gastrointestinal tract (Hammon et al., 2013). Nevertheless, research is still needed to quantify the effect of the differences in colostral components caused by different dry period feeding strategies on gut maturation, metabolism, and growth of the newborn calf.

Another important factor to consider is the volume of colostrum produced. Farms need to collect a enough high-quality colostrum to ensure an optimal colostrum management plan. However, colostrum yield has been traditionally negatively associated with Ig concentration (Pritchett et al., 1991). In addition, several dairy herds have reported a deficiency of colostrum production by cows during fall and winter (Gavin et al., 2018), which limits the ability of farms to feed sufficient highquality colostrum to all their calves. Unfortunately, not much evidence exists regarding the factors influencing the volume of colostrum produced by dairy cows. In the aforementioned study by Mann et al. (2016), no statistical differences in colostrum volume existed among the different dietary plane of energy treatments, although cows fed energy-controlled diet produced numerically less colostrum than those fed the high-energy diet. Also, cows with persistently infected mammary glands produced less colostrum than matched healthy animals (Maunsell et al., 1998). Collectively, these data suggest that prepartum maternal nutrition can affect colostrum production. Clearly, the relationship among prepartum diet, colostrum composition and yield, and calf health and development merits further investigation.

\section{EFFECT OF MATERNAL METABOLIC STATUS}

Despite identical housing and feeding conditions, dairy cows exhibit considerable individual variation in a variety of metabolic and endocrine variables (Kessel et al., 2008). Thus, this review article considers metabolic status during late pregnancy separately from maternal nutrition.

\section{Late-Gestation Metabolic Stress}

Dairy cows experience metabolic stress during the transition period when they fail to physiologically adapt to the profound increase in nutrient requirements associated with fetal growth and milk production (Sordillo and Mavangira, 2014). Metabolic stress is characterized by altered nutrient utilization, OS, and dysfunctional immune and inflammatory responses (Abuelo et al., 2015b). The negative effect of metabolic stress on the immune function, health, and production of dairy cattle during the periparturient period is well established (Kehrli et al., 1989; Sordillo and Aitken, 2009). Metabolic stress is initiated several weeks before calving (Grummer, 1993; Sordillo and Raphael, 2013) and therefore can potentially affect the fetus.

Evidence from other species also supports the fact that exposure to metabolic stress during pregnancy affects the robustness of immune response of the offspring to a challenge during the neonatal stage. For example, rats exposed to a proinflammatory stimulus during late gestation produced offspring with a significantly lower tumor necrosis factor $\alpha(\mathbf{T N F} \boldsymbol{\alpha})$ response to LPS stimulation (Hodyl et al., 2007; Hodyl et al., 2008; Beloosesky et al., 2010). Furthermore, high maternal inflammation during gestation was positively associated with development of wheezing and recurrent respiratory tract infections in infants during the first 14 mo of life (Morales et al., 2011). Also, maternal markers of OS in humans were positively associated in the offspring with the umbilical cord blood concentration of the proinflammatory cytokines IP-10 and IL-5 and were negatively associated with that of the anti-inflammatory cytokine IL-4 (Hernandez-Trejo et al., 2017).

In vitro exposure of bovine oocytes and embryos to elevated nonesterified fatty acid (NEFA) concentrations results in differences in methylation and expression of gene networks related to lipid and carbohydrate metabolism, cell death, immune response, and metabolic disorders (Desmet et al., 2016). Hence, it is possible that greater maternal circulating NEFA during late gestation might affect calf development in utero. We recently studied in dairy cattle the association of late-gestation maternal metabolic stress with the immune and metabolic responses of their calves (Ling et al., 2018). Our results suggest that exposure to maternal metabolic stress (altered nutrient utilization, dysregulated inflammation, and OS) may adversely 
affect some metabolic and inflammatory responses of the offspring that could influence disease susceptibility. We monitored the dam's serum oxidant status, NEFA, and haptoglobin concentrations during the last month of gestation. For each of these biomarkers, cows were classified in low and high groups based on the median value of the average concentration of the prepartum samples. Calves born to cows with higher NEFA or oxidant status showed lower BW at birth and throughout the first month of life. However, no association between the degree of maternal metabolic stress and ADG at 4 wk of age was identified, thus indicating that compensatory growth did not occur postnatally in the first 4 wk. However, this study did not explore whether BW matched later in life, making it not possible to know the persistence of the effect in time.

Exposure to higher maternal concentrations of NEFA was also associated with greater serum concentrations of reactive oxygen and nitrogen species, which resulted in higher values of oxidant status index in the calves throughout their first month of life. To the authors' knowledge, the effect of maternal NEFA concentration during late gestation on the oxidative status of the offspring in postnatal life has not yet been investigated. The mechanism by which prenatal exposure to high maternal NEFA concentrations in late gestation leads to an increased oxidant status is unknown. However, in vitro studies demonstrate that fatty acids may induce cellular production of reactive oxygen species directly (Inoguchi et al., 2000; Listenberger et al., 2001) and indirectly by stimulating inflammatory pathways (Ohtsu et al., 2017). Furthermore, in vitro studies in bovine oocytes and blastocysts demonstrate that elevated NEFA concentrations alter gene expression related to oxidative metabolism (Van Hoeck et al., 2013; Van Hoeck et al., 2015). However, it is yet to be determined whether prenatal exposure to high maternal NEFA concentrations during late gestation influences the expression of genes related to redox homeostasis. Further research is required to determine whether offspring exposed to high maternal NEFA concentrations during late gestation are at increased risk of diseases associated with OS, such as diarrhea, pneumonia, and mastitis (Ranjan et al., 2006; Lykkesfeldt and Svendsen, 2007).

Calves exposed to high maternal oxidant status also had greater circulating concentrations of haptoglobin and $\mathrm{TNF}$, indicating greater basal inflammatory responses when compared with calves born to cows with a lower oxidant status. The clinical significance of elevated $\mathrm{TNF} \alpha$ and haptoglobin concentrations during the first month of life is unknown. Further research is warranted to determine whether an elevated basal inflammatory status during this period is associated with adverse health and production outcomes. Murray et al. (2014) reported that serum haptoglobin concentrations in dairy calves during the first week of life are positively associated with morbidity and mortality during the first 4 mo of life. Furthermore, elevated TNFo concentrations contribute to impaired metabolic function in dairy cattle (McCarthy et al., 2016) and may adversely affect growth rates by inhibition of IGF-1 (Suda et al., 2003; Borghetti et al., 2009). The relationship between the level of basal inflammation during the neonatal period and the development of dysregulated inflammatory responses later in life is also unknown. This is of particular interest because dysregulated inflammation in dairy cattle is highly implicated in the pathogenesis of metabolic stress during the transition period and inflammatory-based diseases, such as mastitis and endometritis (LeBlanc, 2014; Sordillo and Mavangira, 2014)

In contrast, LPS-induced inflammatory responses were less robust in calves exposed to higher maternal biomarkers of inflammation or oxidant status, suggesting compromised immune responses to microbial agonists (Ling et al., 2018). However, it is unknown whether the resulting differences in immune responses in these calves is substantial enough to actually increase their risk of infectious disease. Hence, further studies should evaluate the effect of late-gestation inflammation and OS on neonatal calf disease susceptibility.

\section{OS in Developmental Programming}

Oxidative stress, a component of metabolic stress, plays an important role in developmental programming (Thompson and Al-Hasan, 2012). Oxidants can induce genetic changes by oxidation of DNA (Thompson and Al-Hasan, 2012) and epigenetic alterations by DNA methylation and histone modification (Ziech et al., 2011). Studies in rats and guinea pigs have also demonstrated that phenotypic alterations resulting from suboptimal intrauterine environments can be prevented by prenatal antioxidant supplementation (Cambonie et al., 2007; Evans et al., 2012). In addition to changes in gene and protein expression, OS can also contribute to the creation of an abnormal environment for the fetus to develop through changes in maternal metabolic function (Alfaradhi and Ozanne, 2011). In humans, maternal OS results in obesity, insulin resistance, and diabetes through interference of insulin signaling (Urakawa et al., 2003; Furukawa et al., 2004). Exposure to these conditions during gestation increases the risk of developing metabolic syndrome in the offspring (Alfaradhi and Ozanne, 2011). In fact, altered insulin signaling in offspring of obese or overfed mothers has 
been reported with increased inflammation and OS in various models (Bruce et al., 2009; McCurdy et al., 2009). Nevertheless, reducing the degree of OS results in the reversal in the metabolic syndrome phenotype of the offspring. Sen and Simmons (2010) reported that vitamin $\mathrm{C}$ antioxidant supplementation to pregnant rats fed a high-fat diet decreased adiposity, normalized glucose tolerance, and reduced OS and inflammation in their offspring. Thus, in this model of human disease, maternal OS negatively affects the growth and health of the offspring.

Studies performed in the last decade clearly indicate that dairy cows experience OS around the time of calving (Castillo et al., 2003, 2005; Sordillo and Aitken, 2009; Abuelo et al., 2013; 2015a). Oxidative stress during this time diminishes functional capabilities of immune cell populations, increases the cow's susceptibility to several diseases (Sordillo and Aitken, 2009; Abuelo et al., 2019b), and results in altered immune responses in the offspring (Ling et al., 2018). Furthermore, as in humans, an association between insulin sensitivity and OS has also been reported in periparturient cattle (Abuelo et al., 2016c), with antioxidant supplementation resulting in improved insulin sensitivity (Abuelo et al., 2016a). Therefore, it is possible that OS in dairy cattle also affects developmental programming through changes in gene and protein expression and insulin signaling. Thus, controlling prepartum OS through micronutrient antioxidant supplementation might help ameliorate the phenotypical changes associated with different maternal stressors given the central role of OS in key mechanisms of developmental programming.

\section{SUPPLEMENTATION STRATEGIES}

Supplementation of specific nutrients above requirements during gestation is common practice in humans and livestock species (Cooke, 2019). In dairy cows, supplementation strategies during late gestation are usually implemented on farms to promote transition cow health. Some of these strategies, however, have been shown to affect offspring development and health and are discussed below.

\section{Trace Minerals}

Trace minerals are essential for the adequate development of fetal nervous, immune, and reproductive systems, and the fetus depends completely on the dam for supply of these elements (Hidiroglou and Knipfel, 1981). Many trace minerals can cross the placenta in ruminants. Furthermore, recent evidence analyzing dam and fetal liver mineral content suggests a high maternal to fetal transfer at low maternal mineral concentration but a more limited transfer as maternal mineral content increases (Van Saun, 2019). The effects of supplementing dams during late gestation with trace minerals has been examined in beef and dairy cattle. Marques et al. (2016) compared the supplementation of inorganic and organic sources of $\mathrm{Cu}, \mathrm{Co}, \mathrm{Mn}$, and $\mathrm{Zn}$ during the last trimester of gestation in beef cows. They found no differences in birth BW among treatment (organic and inorganic trace minerals) and control groups. However, the calves born to cows that received the organic-complexed source of trace minerals had increased weight at 205-d weaning and lower incidence of respiratory disease during the feedlot phase. Organic sources of trace minerals are more bioavailable than inorganic ones. Therefore, cows receiving organic sources of trace minerals likely had more trace minerals available to supply the fetus. This study did not report feed intake, and therefore it is not possible to evaluate whether the differences in growth observed are due to increased feed intake or feed efficiency. Nevertheless, it clearly documents how maternal nutritional interventions can have relative long-term implications on the growth and health of the offspring.

Supplementation of organic sources of trace minerals to dairy cows during late gestation also resulted in no differences in calf birth BW compared with cows receiving inorganic sources (Jacometo et al., 2015). However, in contrast to the study in beef cows, no differences in BW existed between the 2 groups throughout the first $8 \mathrm{wk}$ of life. Nevertheless, it is possible that the differences in growth associated with greater in utero trace mineral supply take place later in life. Maternal nutrition with organic trace minerals also resulted in decreased pro-oxidant load, greater expression of key redox transcription factors, and changes in neutrophil mRNA and microRNA expression (Jacometo et al., 2015). Further studies are still needed, however, to determine the effects of maternal trace mineral supplementation on calf immunocompetence and susceptibility to diseases. Also, as discussed above, it is important to clarify whether the observed effects of trace minerals are due to their role in redox balance (Abuelo et al., $2016 \mathrm{~b}$ ) or other biological functions.

\section{Fatty Acids}

During gestation, n-3 and n-6 fatty acids are transferred to the fetus through the placenta (Noble et al., 1978). In general terms, the derivatives of $n-6$ fatty acids are considered pro-inflammatory, whereas n-3 derivatives are inflammation pro-resolving (Sordillo, 2018). In humans, children born to woman supplement- 
ed with n-3 fatty acids during pregnancy showed less cases of allergies and asthma (Olsen et al., 2008). Similarly, supplementation of n-3 fatty acids to pregnant sows resulted in increased piglet viability and pre- and postweaning growth (Tanghe and De Smet, 2013).

In ruminants, maternal supplementation of n-6 fatty acids to beef cows enhanced cold tolerance of calves by improving storage and thermogenic capacity of brown adipose tissue (Lammoglia et al., 1999). However, it reduced survival to second parity and increased milk SCC in ewes (Encinias et al., 2004). Research in dairy cows also showed that feeding moderate amounts $(1.7 \%$ of DM) of saturated or unsaturated long-chain fatty acids during the last 8 wk of gestation improved apparent efficiency of absorption of IgG and changed the fatty acid profile of colostrum and plasma of calves to reflect that of the supplements (Garcia et al., 2014). The mechanism behind the differences in apparent efficiency of absorption of IgG associated with fatty acid supplementation are unknown. The authors speculated that it could be attributed to faster gastric emptying associated with a greater fatty acid content of the colostrum in supplemented cows, or to changes in the fatty acid profile of the enterocyte membrane that facilitate the IgG pinocytosis process. Thus, strategic fatty acid supplementation during late gestation has the potential to be used to improve calf survivability, but further research is still needed to optimize the amount of $n-6$ and n-3 fatty acids needed for improved calf health.

\section{Rumen-Protected Methionine}

Another supplementation strategy that has been extensively studied in the last years is the administration of rumen-protected methionine during late gestation. Methionine is an EAA, and its metabolism can generate the antioxidants taurine and glutathione (Zhou et al., 2016). The provision of AA to the dam can ameliorate the effects of fetal growth restriction due to undernutrition and improve health and growth of offspring (Lin et al., 2014). Methionine supply during late gestation resulted in changes in placental metabolism and DNA methylation in a calf sex-specific manner (Batistel et al., 2019). Calves born to cows that received methionine during late gestation were heavier at birth $(+2 \mathrm{~kg})$ and at 9 wk of age $(+3.1 \mathrm{~kg})$, also exhibiting greater ADG $(+0.05 \mathrm{~kg} / \mathrm{d})$ despite no differences in feed intake compared with the control group (Alharthi et al., 2017). Thus, maternal methionine supplementation resulted in improved feed efficiency during the 9 -wk duration of the study.

Calves born to supplemented cows also showed higher plasma concentrations on insulin and lower plasma concentrations of glucose, along with decreased glucose-to-insulin and fatty acids-to-insulin ratios (Jacometo et al., 2016), which is suggestive of improved insulin sensitivity in these animals. Hepatic gene transcriptomic analyses also revealed a faster maturation of key metabolic pathways in calves born to supplemented dams, as shown by the upregulation of genes related to gluconeogenesis and fatty acid oxidation along with insulin sensitivity earlier in life. However, the supplementation had no effect on the inflammatory or oxidant status of calves throughout the first 9 wk of life. More recently, the same authors also reported changes in the calf leukocyte mRNA expression of some genes related to cell adhesion and chemotaxis and the toll-like receptor pathway (Jacometo et al., 2018). This indicates changes in the immune function of calves born to supplemented cows. However, no differences existed in the LPS-induced cytokine-release response between calves born to supplemented and unsupplemented cows (Jacometo et al., 2018). Hence, it remains unclear whether the changes observed in gene expression translate to an increased ability to fight infections. Thus, further work should evaluate the effect of these interventions in calf disease susceptibility.

\section{CONCLUSIONS}

Substantial evidence exists in dairy cattle supporting the effects of late gestation maternal stressors or other interventions that, when imposed on the mother, affect neonatal development, health, and lifetime production. In this line, given the central role of OS in the various processes implicated in developmental programing, further studies are needed to investigate the short- and long-term effects that ameliorating late-gestation OS might have on the development of immune and metabolic function of the offspring. Thus, increasing our understanding of the underlying mechanisms of developmental programming will lead to dry-cow management programs aimed at improving not only early lactation cow health but also neonatal calf growth and immunity. Also, more research is still needed to evaluate the effects of different interventions on the immunocompetence and disease resistance of the calf.

\section{ACKNOWLEDGMENTS}

This work was supported by the Animal Health project 1016161 and the Agriculture and Food Research Initiative Competitive Grant no. 2018-67015-28302 from the USDA National Institute of Food and Agriculture (Washington, DC), and the AA19-02 grant of the Michigan Alliance for Animal Agriculture (East 
Lansing, MI). The author has not stated any conflicts of interest.

\section{REFERENCES}

Abuelo, A., V. Alves-Nores, J. Hernandez, R. Muino, J. L. Benedito, and C. Castillo. 2016a. Effect of parenteral antioxidant supplementation during the dry period on postpartum glucose tolerance in dairy cows. J. Vet. Intern. Med. 30:892-898. https://doi.org/10 .1111 /jvim. 13922 .

Abuelo, A., P. Havrlant, N. Wood, and M. Hernandez-Jover. 2019a. An investigation of dairy calf management practices, colostrum quality, failure of transfer of passive immunity, and occurrence of enteropathogens among Australian dairy farms. J. Dairy Sci. 102:8352-8366. https://doi.org/10.3168/jds.2019-16578.

Abuelo, A., J. Hernandez, V. Alves-Nores, J. L. Benedito, and C. Castillo. 2016b. Association of serum concentration of different trace elements with biomarkers of systemic oxidant status in dairy cattle. Biol. Trace Elem. Res. 174:319-324. https://doi.org/10 .1007/s12011-016-0713-4.

Abuelo, A., J. Hernandez, J. L. Benedito, and C. Castillo. 2013. Oxidative stress index (OSi) as a new tool to assess redox status in dairy cattle during the transition period. Animal 7:1374-1378. https://doi.org/10.1017/S1751731113000396.

Abuelo, A., J. Hernandez, J. L. Benedito, and C. Castillo. 2015a. A pilot study to compare oxidative status between organically and conventionally managed dairy cattle during the transition period. Reprod. Domest. Anim. 50:538-544. https://doi.org/10.1111/rda .12519 .

Abuelo, A., J. Hernandez, J. L. Benedito, and C. Castillo. 2015b. The importance of the oxidative status of dairy cattle in the periparturient period: Revisiting antioxidant supplementation. J. Anim. Physiol. Anim. Nutr. (Berl.) 99:1003-1016. https://doi.org/10 $.1111 /$ jpn. 12273 .

Abuelo, A., J. Hernandez, J. L. Benedito, and C. Castillo. 2016c. Association of oxidative status and insulin sensitivity in periparturient dairy cattle: An observational study. J. Anim. Physiol. Anim. Nutr. (Berl.) 100:279-286. https://doi.org/10.1111/jpn.12365.

Abuelo, A., J. Hernandez, J. L. Benedito, and C. Castillo. 2019b. Redox biology in transition periods of dairy cattle: Role in the health of periparturient and neonatal animals. Antioxidants 8:20. https:/ /doi.org/10.3390/antiox8010020.

Alfaradhi, M. Z., and S. E. Ozanne. 2011. Developmental programming in response to maternal overnutrition. Front. Genet. 2:27. https://doi.org/10.3389/fgene.2011.00027.

Alharthi, A. S. M., F. Batistel, C. Parys, A. Helmbrecht, and J. Loor. 2017. Maternal rumen-protected methionine supplementation during late-pregnancy affects calf development and growth during early postnatal life. FASEB J. 31(1_Suppl.):lb293-lb293.

Barker, D. J. 2007. The origins of the developmental origins theory. J. Intern. Med. 261:412-417. https://doi.org/10.1111/j.1365-2796 .2007.01809.x.

Batistel, F., A. S. Alharthi, R. R. C. Yambao, A. A. Elolimy, Y. X. Pan, C. Parys, and J. J. Loor. 2019. Methionine supply during late-gestation triggers offspring sex-specific divergent changes in metabolic and epigenetic signatures in bovine placenta. J. Nutr. 149:6-17. https://doi.org/10.1093/jn/nxy240.

Beloosesky, R., N. Maravi, Z. Weiner, N. Khatib, N. Awad, J. Boles, M. G. Ross, and J. Itskovitz-Eldor. 2010. Maternal lipopolysaccharide-induced inflammation during pregnancy programs impaired offspring innate immune responses. Am. J. Obstet. Gynecol. 203(2):185.e1-185.e4. https://doi.org/10.1016/j.ajog.2010.04.033.

Berry, D. P., P. Lonergan, S. T. Butler, A. R. Cromie, T. Fair, F. Mossa, and A. C. Evans. 2008. Negative influence of high maternal milk production before and after conception on offspring survival and milk production in dairy cattle. J. Dairy Sci. 91:329-337. https://doi.org/10.3168/jds.2007-0438.

Besser, T. E., and C. C. Gay. 1994. The importance of colostrum to the health of the neonatal calf. Vet. Clin. North Am. Food Anim.
Pract. 10:107-117. https://doi.org/10.1016/S0749-0720(15)30591 -0 .

Blecha, F., R. C. Bull, D. P. Olson, R. H. Ross, and S. Curtis. 1981. Effects of prepartum protein restriction in the beef cow on immunoglobin content in blood and colostral whey and subsequent immunoglobin absorption by the neonatal calf. J. Anim. Sci 53:1174-1180. https://doi.org/10.2527/jas1981.5351174x.

Borengasser, S. J., F. Lau, P. Kang, M. L. Blackburn, M. J. Ronis, T. M. Badger, and K. Shankar. 2011. Maternal obesity during gestation impairs fatty acid oxidation and mitochondrial SIRT3 expression in rat offspring at weaning. PLoS One 6:e24068. https: //doi.org/10.1371/journal.pone.0024068.

Borghetti, P., R. Saleri, E. Mocchegiani, A. Corradi, and P. Martelli. 2009. Infection, immunity and the neuroendocrine response. Vet. Immunol. Immunopathol. 130:141-162. https://doi.org/10.1016/j .vetimm.2009.01.013.

Brandon, M. R., D. L. Watson, and A. K. Lascelles. 1971. The mechanism of transfer of immunoglobulin into mammary secretion of cows. Aust. J. Exp. Biol. Med. Sci. 49:613-623. https://doi.org/10 $.1038 /$ icb.1971.67.

Bruce, K. D., F. R. Cagampang, M. Argenton, J. Zhang, P. L. Ethirajan, G. C. Burdge, A. C. Bateman, G. F. Clough, L. Poston, M. A. Hanson, J. M. McConnell, and C. D. Byrne. 2009. Maternal highfat feeding primes steatohepatitis in adult mice offspring, involving mitochondrial dysfunction and altered lipogenesis gene expression. Hepatology 50:1796-1808. https://doi.org/10.1002/hep.23205.

Cambonie, G., B. Comte, C. Yzydorczyk, T. Ntimbane, N. Germain, N. L. Le, P. Pladys, C. Gauthier, I. Lahaie, D. Abran, J. C. Lavoie, and A. M. Nuyt. 2007. Antenatal antioxidant prevents adult hypertension, vascular dysfunction, and microvascular rarefaction associated with in utero exposure to a low-protein diet. Am. J. Physiol. Regul. Integr. Comp. Physiol. 292:R1236-R1245. https:// doi.org/10.1152/ajpregu.00227.2006.

Castillo, C., J. Hernandez, A. Bravo, M. Lopez-Alonso, V. Pereira, and J. L. Benedito. 2005. Oxidative status during late pregnancy and early lactation in dairy cows. Vet. J. 169:286-292. https://doi.org/ 10.1016/j.tvjl.2004.02.001

Castillo, C., J. Hernandez, M. Lopez-Alonso, M. Miranda, and J. Luis. 2003. Values of plasma lipid hydroperoxides and total antioxidant status in healthy dairy cows: Preliminary observations. Arch. Anim. Breed. 46:227-233. https://doi.org/10.5194/aab-46 $-227-2003$.

Chase, C. C., D. J. Hurley, and A. J. Reber. 2008. Neonatal immune development in the calf and its impact on vaccine response. Vet. Clin. North Am. Food Anim. Pract. 24:87-104. https://doi.org/10 .1016/j.cvfa.2007.11.001.

Chavatte-Palmer, P., C. Richard, P. Peugnet, M. Robles, D. Rousseau-Ralliard, and A. Tarrade. 2015. The developmental origins of health and disease: Importance for animal production. Anim. Reprod. 12:505-520.

Chebel, R. C., L. G. D. Mendonca, and P. S. Baruselli. 2018. Association between body condition score change during the dry period and postpartum health and performance. J. Dairy Sci. 101:45954614. https://doi.org/10.3168/jds.2017-13732.

Collazos, C., C. Lopera, J. E. P. Santos, and J. Laporta. 2017. Effects of the level and duration of maternal diets with negative dietary cation-anion differences prepartum on calf growth, immunity, and mineral and energy metabolism. J. Dairy Sci. 100:9835-9850. https://doi.org/10.3168/jds.2017-13200.

Cooke, R. F. 2019. Effects on animal health and immune function. Vet. Clin. North Am. Food Anim. Pract. 35:331-341. https://doi.org/ 10.1016/j.cvfa.2019.02.004.

Dahl, G. E., S. Tao, and A. P. A. Monteiro. 2016. Effects of lategestation heat stress on immunity and performance of calves. J. Dairy Sci. 99:3193-3198. https://doi.org/10.3168/jds.2015-9990.

Dalcq, A. C., Y. Beckers, P. Mayeres, E. Reding, B. Wyzen, F. Colinet, P. Delhez, and H. Soyeurt. 2018. The feeding system impacts relationships between calving interval and economic results of dairy farms. Animal 12:1662-1671. https://doi.org/10.1017/ S1751731117003020. 
De Koster, J., and G. Opsomer. 2012. Are modern dairy cows suffering from modern diseases? Vlaams Diergeneeskd. Tijdschr. 81:71-80.

Desmet, K. L., V. Van Hoeck, D. Gagne, E. Fournier, A. Thakur, A. M. O'Doherty, C. P. Walsh, M. A. Sirard, P. E. Bols, and J. L. Leroy. 2016. Exposure of bovine oocytes and embryos to elevated non-esterified fatty acid concentrations: Integration of epigenetic and transcriptomic signatures in resultant blastocysts. BMC Genomics 17:1004. https://doi.org/10.1186/s12864-016-3366-y.

Diehl, A. L., J. K. Bernard, S. Tao, T. N. Smith, T. Marins, D. J. Kirk, D. J. McLean, and J. D. Chapman. 2018. Short communication: Blood mineral and gas concentrations of calves born to cows fed prepartum diets differing in dietary cation-anion difference and calcium concentration. J. Dairy Sci. 101:9048-9051. https://doi .org/10.3168/jds.2018-14829.

Du, M., J. Tong, J. Zhao, K. R. Underwood, M. Zhu, S. P. Ford, and P. W. Nathanielsz. 2010. Fetal programming of skeletal muscle development in ruminant animals. J. Anim. Sci. 88(Suppl._13):E51E60. https://doi.org/10.2527/jas.2009-2311.

Duarte, M. S., M. P. Gionbelli, P. V. Paulino, N. V. Serao, C. S. Nascimento, M. E. Botelho, T. S. Martins, S. C. Filho, M. V. Dodson, S. E. Guimaraes, and M. Du. 2014. Maternal overnutrition enhances mRNA expression of adipogenic markers and collagen deposition in skeletal muscle of beef cattle fetuses. J. Anim. Sci. 92:3846-3854. https://doi.org/10.2527/jas.2014-7568.

Elolimy, A., M. Vailati-Riboni, Y. Liang, and J. J. Loor. 2019. Cellular mechanisms and epigenetic changes: Role of nutrition in livestock. Vet. Clin. North Am. Food Anim. Pract. 35:249-263. https://doi .org/10.1016/j.cvfa.2018.12.001.

Encinias, H. B., G. P. Lardy, A. M. Encinias, and M. L. Bauer. 2004 High linoleic acid safflower seed supplementation for gestating ewes: Effects on ewe performance, lamb survival, and brown fat stores. J. Anim. Sci. 82:3654-3661. https://doi.org/10.2527/2004 $.82123654 \mathrm{x}$.

Evans, L. C., H. Liu, G. A. Pinkas, and L. P. Thompson. 2012. Chronic hypoxia increases peroxynitrite, $M M P 9$ expression, and collagen accumulation in fetal guinea pig hearts. Pediatr. Res. 71:25-31. https://doi.org/10.1038/pr.2011.10.

Faber, S. N., N. E. Faber, T. C. McCauley, and R. L. Ax. 2005. Effects of colostrum ingestion on lactational performance. Prof. Anim. Sci. 21:420-425. https://doi.org/10.15232/S1080-7446(15)31240-7.

Feve, B. 2005. Adipogenesis: Cellular and molecular aspects. Best Pract. Res. Clin. Endocrinol. Metab. 19:483-499. https://doi.org/ 10.1016/j.beem.2005.07.007.

Furukawa, S., T. Fujita, M. Shimabukuro, M. Iwaki, Y. Yamada, Y. Nakajima, O. Nakayama, M. Makishima, M. Matsuda, and I. Shimomura. 2004. Increased oxidative stress in obesity and its impact on metabolic syndrome. J. Clin. Invest. 114:1752-1761. https://doi .org/10.1172/JCI21625.

Gaccioli, F., S. Lager, T. L. Powell, and T. Jansson. 2013. Placental transport in response to altered maternal nutrition. J. Dev. Orig. Health Dis. 4:101-115. https://doi.org/10.1017/ S2040174412000529.

Garcia, M., L. F. Greco, M. G. Favoreto, R. S. Marsola, L. T. Martins, R. S. Bisinotto, J. H. Shin, A. L. Lock, E. Block, W. W. Thatcher, J. E. Santos, and C. R. Staples. 2014. Effect of supplementing fat to pregnant nonlactating cows on colostral fatty acid profile and passive immunity of the newborn calf. J. Dairy Sci. 97:392-405. https://doi.org/10.3168/jds.2013-7086.

Gavin, K., H. Neibergs, A. Hoffman, J. N. Kiser, M. A. Cornmesser, S. A. Haredasht, B. Martinez-Lopez, J. R. Wenz, and D. A. Moore. 2018. Low colostrum yield in Jersey cattle and potential risk factors. J. Dairy Sci. 101:6388-6398. https://doi.org/10.3168/ jds.2017-14308.

Godden, S. 2008. Colostrum management for dairy calves. Vet. Clin. North Am. Food Anim. Pract. 24:19-39. https://doi.org/10.1016/ j.cvfa.2007.10.005.

Godden, S. M., J. E. Lombard, and A. R. Woolums. 2019. Colostrum management for dairy calves. Vet. Clin. North Am. Food Anim. Pract. 35:535-556. https://doi.org/10.1016/j.cvfa.2019.07.005.

Goff, J. P. 2006. Macromineral physiology and application to the feeding of the dairy cow for prevention of milk fever and other peripar- turient mineral disorders. Anim. Feed Sci. Technol. 126:237-257. https://doi.org/10.1016/j.anifeedsci.2005.08.005.

Gonzalez-Recio, O., E. Ugarte, and A. Bach. 2012. Trans-generational effect of maternal lactation during pregnancy: A Holstein cow model. PLoS One 7:e51816. https://doi.org/10.1371/journal.pone .0051816 .

Grummer, R. R. 1993. Etiology of lipid-related metabolic disorders in periparturient dairy cows. J. Dairy Sci. 76:3882-3896. https://doi .org/10.3168/jds.S0022-0302(93)77729-2.

Hammon, H. M., J. Steinhoff-Wagner, J. Flor, U. Schonhusen, and C. C. Metges. 2013. Lactation Biology Symposium: Role of colostrum and colostrum components on glucose metabolism in neonatal calves. J. Anim. Sci. 91:685-695. https://doi.org/10.2527/jas $.2012-5758$.

Hernandez-Trejo, M., A. Montoya-Estrada, Y. Torres-Ramos, A. Espejel-Nunez, A. Guzman-Grenfell, R. Morales-Hernandez, M. Tolentino-Dolores, and E. Laresgoiti-Servitje. 2017. Oxidative stress biomarkers and their relationship with cytokine concentrations in overweight/obese pregnant women and their neonates. BMC Immunol. 18:3. https://doi.org/10.1186/s12865-016-0184-6.

Hidiroglou, M., and J. E. Knipfel. 1981. Maternal-fetal relationships of copper, manganese, and sulfur in ruminants. A review. J. Dairy Sci. 64:1637-1647. https://doi.org/10.3168/jds.S0022 $-0302(81) 82741-5$.

Higgins, D. A., M. J. Stack, and C. Richardson. 1983. Lymphocyte markers in the bovine foetus. Dev. Comp. Immunol. 7:369-377. https://doi.org/10.1016/0145-305X(83)90018-6.

Hodyl, N. A., K. M. Krivanek, V. L. Clifton, and D. M. Hodgson. 2008. Innate immune dysfunction in the neonatal rat following prenatal endotoxin exposure. J. Neuroimmunol. 204:126-130. https:// doi.org/10.1016/j.jneuroim.2008.06.041.

Hodyl, N. A., K. M. Krivanek, E. Lawrence, V. L. Clifton, and D. M. Hodgson. 2007. Prenatal exposure to a pro-inflammatory stimulus causes delays in the development of the innate immune response to LPS in the offspring. J. Neuroimmunol. 190:61-71. https://doi .org/10.1016/j.jneuroim.2007.07.021.

Hough, R. L., F. D. McCarthy, H. D. Kent, D. E. Eversole, and M. L. Wahlberg. 1990. Influence of nutritional restriction during late gestation on production measures and passive immunity in beef cattle. J. Anim. Sci. 68:2622-2627. https://doi.org/10.2527/1990 $.6892622 \mathrm{x}$

Hyatt, M. A., H. Budge, and M. E. Symonds. 2008. Early developmental influences on hepatic organogenesis. Organogenesis 4:170-175. https://doi.org/10.4161/org.4.3.6849.

Inoguchi, T., P. Li, F. Umeda, H. Y. Yu, M. Kakimoto, M. Imamura, T. Aoki, T. Etoh, T. Hashimoto, M. Naruse, H. Sano, H. Utsumi, and H. Nawata. 2000. High glucose level and free fatty acid stimulate reactive oxygen species production through protein kinase $\mathrm{C}-$ dependent activation of $\mathrm{NAD}(\mathrm{P}) \mathrm{H}$ oxidase in cultured vascular cells. Diabetes 49:1939-1945. https://doi.org/10.2337/diabetes.49 .11 .1939

Jacometo, C. B., A. S. Alharthi, Z. Zhou, D. Luchini, and J. J. Loor. 2018. Maternal supply of methionine during late pregnancy is associated with changes in immune function and abundance of microRNA and mRNA in Holstein calf polymorphonuclear leukocytes. J. Dairy Sci. 101:8146-8158. https://doi.org/10.3168/jds .2018-14428.

Jacometo, C. B., J. S. Osorio, M. Socha, M. N. Correa, F. PiccioliCappelli, E. Trevisi, and J. J. Loor. 2015. Maternal consumption of organic trace minerals alters calf systemic and neutrophil mRNA and microRNA indicators of inflammation and oxidative stress. J. Dairy Sci. 98:7717-7729. https://doi.org/10.3168/jds.2015-9359.

Jacometo, C. B., Z. Zhou, D. Luchini, E. Trevisi, M. N. Correa, and J. J. Loor. 2016. Maternal rumen-protected methionine supplementation and its effect on blood and liver biomarkers of energy metabolism, inflammation, and oxidative stress in neonatal Holstein calves. J. Dairy Sci. 99:6753-6763. https://doi.org/10.3168/ jds.2016-11018.

Jones, C. M., R. E. James, J. D. Quigley 3rd, and M. L. McGilliard. 2004. Influence of pooled colostrum or colostrum replacement on IgG and evaluation of animal plasma in milk replacer. J. Dairy Sci. 
87:1806-1814. https://doi.org/10.3168/jds.S0022-0302(04)73337 $-8$.

Kehrli, M. E., Jr., B. J. Nonnecke, and J. A. Roth. 1989. Alterations in bovine neutrophil function during the periparturient period. Am. J. Vet. Res. 50:207-214.

Kessel, S., M. Stroehl, H. H. Meyer, S. Hiss, H. Sauerwein, F. J. Schwarz, and R. M. Bruckmaier. 2008. Individual variability in physiological adaptation to metabolic stress during early lactation in dairy cows kept under equal conditions. J. Anim. Sci. 86:29032912. https://doi.org/10.2527/jas.2008-1016.

Lammoglia, M. A., R. A. Bellows, E. E. Grings, J. W. Bergman, R. E. Short, and M. D. MacNeil. 1999. Effects of feeding beef females supplemental fat during gestation on cold tolerance in newborn calves. J. Anim. Sci. 77:824-834. https://doi.org/10.2527/1999 $.774824 \mathrm{x}$

Lean, I. J., P. J. DeGaris, D. M. McNeil, and E. Block. 2006. Hypocalcemia in dairy cows: Meta-analysis and dietary cation anion difference theory revisited. J. Dairy Sci. 89:669-684. https://doi .org/10.3168/jds.S0022-0302(06)72130-0.

Lean, I. J., J. E. P. Santos, E. Block, and H. M. Golder. 2019. Effects of prepartum dietary cation-anion difference intake on production and health of dairy cows: A meta-analysis. J. Dairy Sci. 102:21032133. https://doi.org/10.3168/jds.2018-14769.

LeBlanc, S. J. 2014. Reproductive tract inflammatory disease in postpartum dairy cows. Animal 8(Suppl 1):54-63. https://doi.org/10 $.1017 /$ S1751731114000524.

Lin, G., X. Wang, G. Wu, C. Feng, H. Zhou, D. Li, and J. Wang. 2014. Improving amino acid nutrition to prevent intrauterine growth restriction in mammals. Amino Acids 46:1605-1623. https://doi .org/10.1007/s00726-014-1725-z.

Ling, T., M. Hernandez-Jover, L. M. Sordillo, and A. Abuelo. 2018. Maternal late-gestation metabolic stress is associated with changes in immune and metabolic responses of dairy calves. J. Dairy Sci. 101:6568-6580. https://doi.org/10.3168/jds.2017-14038.

Listenberger, L. L., D. S. Ory, and J. E. Schaffer. 2001. Palmitate-induced apoptosis can occur through a ceramide-independent pathway. J. Biol. Chem. 276:14890-14895. https://doi.org/10.1074/jbc .M010286200.

Luo, Z. C., W. D. Fraser, P. Julien, C. L. Deal, F. Audibert, G. N. Smith, X. Xiong, and M. Walker. 2006. Tracing the origins of "fetal origins" of adult diseases: Programming by oxidative stress? Med. Hypotheses 66:38-44. https://doi.org/10.1016/j.mehy.2005 .08 .020 .

Lykkesfeldt, J., and O. Svendsen. 2007. Oxidants and antioxidants in disease: Oxidative stress in farm animals. Vet. J. 173:502-511. https://doi.org/10.1016/j.tvjl.2006.06.005.

Mann, S., F. A. Leal Yepes, T. R. Overton, A. L. Lock, S. V. Lamb, J. J. Wakshlag, and D. V. Nydam. 2016. Effect of dry period dietary energy level in dairy cattle on volume, concentrations of immunoglobulin G, insulin, and fatty acid composition of colostrum. J. Dairy Sci. 99:1515-1526. https://doi.org/10.3168/jds.2015-9926.

Marques, R. S., R. F. Cooke, M. C. Rodrigues, B. I. Cappellozza, R. R. Mills, C. K. Larson, P. Moriel, and D. W. Bohnert. 2016. Effects of organic or inorganic cobalt, copper, manganese, and zinc supplementation to late-gestating beef cows on productive and physiological responses of the offspring. J. Anim. Sci. 94:1215-1226. https://doi.org/10.2527/jas.2015-0036.

Maunsell, F. P., D. E. Morin, P. D. Constable, W. L. Hurley, G. C. McCoy, I. Kakoma, and R. E. Isaacson. 1998. Effects of mastitis on the volume and composition of colostrum produced by Holstein cows. J. Dairy Sci. 81:1291-1299. https://doi.org/10.3168/ jds.S0022-0302(98)75691-7.

McCarthy, M. M., T. Yasui, M. J. Felippe, and T. R. Overton. 2016. Associations between the degree of early lactation inflammation and performance, metabolism, and immune function in dairy cows. J. Dairy Sci. 99:680-700. https://doi.org/10.3168/jds.2015-9694.

McCurdy, C. E., J. M. Bishop, S. M. Williams, B. E. Grayson, M. S. Smith, J. E. Friedman, and K. L. Grove. 2009. Maternal high-fat diet triggers lipotoxicity in the fetal livers of nonhuman primates. J. Clin. Invest. 119:323-335. https://doi.org/10.1172/JCI32661.
Morales, E., S. Guerra, R. Garcia-Esteban, M. Guxens, M. AlvarezPedrerol, M. Bustamante, X. Estivill, J. M. Anto, and J. Sunyer. 2011. Maternal C-reactive protein levels in pregnancy are associated with wheezing and lower respiratory tract infections in the offspring. Am. J. Obstet. Gynecol. 204(2):164.e1-164.e9. https:// doi.org/10.1016/j.ajog.2010.08.056.

Moriel, P., M. B. Piccolo, L. F. Artioli, R. S. Marques, M. H. Poore, and R. F. Cooke. 2016. Short-term energy restriction during late gestation of beef cows decreases postweaning calf humoral immune response to vaccination. J. Anim. Sci. 94:2542-2552. https://doi .org/10.2527/jas.2016-0426.

Morrill, K. M., S. P. Marston, N. L. Whitehouse, M. E. Van Amburgh, C. G. Schwab, D. M. Haines, and P. S. Erickson. 2010. Anionic salts in the prepartum diet and addition of sodium bicarbonate to colostrum replacer, and their effects on immunoglobulin G absorption in the neonate. J. Dairy Sci. 93:2067-2075. https://doi.org/10 $.3168 /$ jds.2009-2622.

Murray, C. F., M. C. Windeyer, T. F. Duffield, D. B. Haley, D. L. Pearl, K. M. Waalderbos, and K. E. Leslie. 2014. Associations of serum haptoglobin in newborn dairy calves with health, growth, and mortality up to 4 months of age. J. Dairy Sci. 97:7844-7855. https://doi.org/10.3168/jds.2014-8465.

NAHMS (National Animal Health Monitoring Service). 2014. Dairy 2014. Part 1: Reference of Dairy Health and Management in the United States. USDA, Anim. Plant Health Inspect. Serv., Vet. Serv., Ft. Collins, CO.

NAHMS (National Animal Health Monitoring Service). 2007. Dairy Heifer Morbidity, Mortality and Health Management Practices Focusing on Preweaned Heifers. USDA, Anim. Plant Health Inspect. Serv., Vet. Serv., Ft. Collins, CO.

Noble, R. C., J. H. Shand, J. T. Drummond, and J. H. Moore. 1978. "Protected" polyunsaturated fatty acid in the diet of the ewe and the essential fatty acid status of the neonatal lamb. J. Nutr. 108:1868-1876. https://doi.org/10.1093/jn/108.11.1868.

Ohtsu, A., H. Tanaka, K. Seno, H. Iwata, T. Kuwayama, and K. Shirasuna. 2017. Palmitic acid stimulates interleukin-8 via the TLR4/ NF-kappaB/ROS pathway and induces mitochondrial dysfunction in bovine oviduct epithelial cells. Am. J. Reprod. Immunol 77:e12642. https://doi.org/10.1111/aji.12642.

Olsen, S. F., M. L. Osterdal, J. D. Salvig, L. M. Mortensen, D. Rytter, N. J. Secher, and T. B. Henriksen. 2008. Fish oil intake compared with olive oil intake in late pregnancy and asthma in the offspring: $16 \mathrm{y}$ of registry-based follow-up from a randomized controlled trial. Am. J. Clin. Nutr. 88:167-175. https://doi.org/10.1093/ajcn/88 .1 .167 .

Opsomer, G., M. Van Eetvelde, M. Kamal, and A. Van Soom. 2016. Epidemiological evidence for metabolic programming in dairy cattle. Reprod. Fertil. Dev. 29:52-57. https://doi.org/10.1071/ RD16410.

Østerås, O., M. S. Gjestvang, S. Vatn, and L. Sølverød. 2007. Perinatal death in production animals in the Nordic countries-Incidence and costs. Acta Vet. Scand. 49(S1):S14. https://doi.org/10.1186/ 1751-0147-49-S1-S14.

Padmanabhan, V., R. C. Cardoso, and M. Puttabyatappa. 2016. Developmental programming, a pathway to disease. Endocrinology 157:1328-1340. https://doi.org/10.1210/en.2016-1003.

Pritchett, L. C., C. C. Gay, T. E. Besser, and D. D. Hancock. 1991. Management and production factors influencing immunoglobulin G1 concentration in colostrum from Holstein cows. J. Dairy Sci 74:2336-2341. https://doi.org/10.3168/jds.S0022-0302(91)78406 $-3$.

Quigley, J. D., 3rd, and J. J. Drewry. 1998. Nutrient and immunity transfer from cow to calf pre- and postcalving. J. Dairy Sci. 81:2779-2790. https://doi.org/10.3168/jds.S0022-0302(98)75836 $-9$.

Ranjan, R., R. Naresh, R. C. Patra, and D. Swarup. 2006. Erythrocyte lipid peroxides and blood zinc and copper concentrations in acute undifferentiated diarrhoea in calves. Vet. Res. Commun. 30:249-254. https://doi.org/10.1007/s11259-006-3185-8.

Reynolds, L. P., P. P. Borowicz, J. S. Caton, M. S. Crouse, C. R. Dahlen, and A. K. Ward. 2019. Developmental programming of 
fetal growth and development. Vet. Clin. North Am. Food Anim. Pract. 35:229-247. https://doi.org/10.1016/j.cvfa.2019.02.006.

Reynolds, L. P., P. P. Borowicz, J. S. Caton, K. A. Vonnahme, J. S. Luther, C. J. Hammer, K. R. Maddock Carlin, A. T. GrazulBilska, and D. A. Redmer. 2010. Developmental programming: The concept, large animal models, and the key role of uteroplacental vascular development. J. Anim. Sci. 88(Suppl._13):E61-E72. https://doi.org/10.2527/jas.2009-2359.

Reynolds, L. P., and J. S. Caton. 2012. Role of the pre- and post-natal environment in developmental programming of health and productivity. Mol. Cell. Endocrinol. 354:54-59. https://doi.org/10.1016/ j.mce.2011.11.013.

Schultz, R. D., H. W. Dunne, and C. E. Heist. 1973. Ontogeny of the bovine immune response. Infect. Immun. 7:981-991.

Sen, S., and R. A. Simmons. 2010. Maternal antioxidant supplementation prevents adiposity in the offspring of Western diet-fed rats. Diabetes 59:3058-3065. https://doi.org/10.2337/db10-0301.

Skibiel, A. L., F. Penagaricano, R. Amorin, B. M. Ahmed, G. E. Dahl, and J. Laporta. 2018. In utero heat stress alters the offspring epigenome. Sci. Rep. 8:14609. https://doi.org/10.1038/s41598-018 $-32975-1$.

Sordillo, L. M. 2018. Symposium review: Oxylipids and the regulation of bovine mammary inflammatory responses. J. Dairy Sci. 101:5629-5641. https://doi.org/10.3168/jds.2017-13855.

Sordillo, L. M., and S. L. Aitken. 2009. Impact of oxidative stress on the health and immune function of dairy cattle. Vet. Immunol. Immunopathol. 128:104-109. https://doi.org/10.1016/j.vetimm.2008 .10 .305 .

Sordillo, L. M., and V. Mavangira. 2014. The nexus between nutrient metabolism, oxidative stress and inflammation in transition cows. Anim. Prod. Sci. 54:1204-1214. https://doi.org/10.1071/AN14503.

Sordillo, L. M., and W. Raphael. 2013. Significance of metabolic stress, lipid mobilization, and inflammation on transition cow disorders. Vet. Clin. North Am. Food Anim. Pract. 29:267-278. https://doi .org/10.1016/j.cvfa.2013.03.002.

Suda, Y., K. Nagaoka, K. Nakagawa, T. Chiba, F. Yusa, H. Shinohara, A. Nihei, and T. Yamagishi. 2003. Change of plasma insulinlike growth factor-1 (IGF-1) concentration with early growth in Japanese beef cattle. Anim. Sci. J. 74:205-210. https://doi.org/10 .1046/j.1344-3941.2003.00106.x.

Tanghe, S., and S. De Smet. 2013. Does sow reproduction and piglet performance benefit from the addition of $n-3$ polyunsaturated fatty acids to the maternal diet? Vet. J. 197:560-569. https://doi .org/10.1016/j.tvjl.2013.03.051.

Tao, S., G. E. Dahl, J. Laporta, J. K. Bernard, R. M. Orellana Rivas, and T. N. Marins. 2019. physiology symposium: Effects of heat stress during late gestation on the dam and its calf. J. Anim. Sci. 97:2245-2257. https://doi.org/10.1093/jas/skz061.

Thompson, L. P., and Y. Al-Hasan. 2012. Impact of oxidative stress in fetal programming. J. Pregnancy 2012:1-8. https://doi.org/10 $.1155 / 2012 / 582748$.

Tucker, W. B., J. F. Hogue, G. D. Adams, M. Aslam, I. S. Shin, and G. Morgan. 1992. Influence of dietary cation-anion balance during the dry period on the occurrence of parturient paresis in cows fed excess calcium. J. Anim. Sci. 70:1238-1250. https://doi.org/10 $.2527 / 1992.7041238 x$.

Urakawa, H., A. Katsuki, Y. Sumida, E. C. Gabazza, S. Murashima, K. Morioka, N. Maruyama, N. Kitagawa, T. Tanaka, Y. Hori, K. Nakatani, Y. Yano, and Y. Adachi. 2003. Oxidative stress is associated with adiposity and insulin resistance in men. J. Clin. Endocrinol. Metab. 88:4673-4676. https://doi.org/10.1210/jc.2003 -030202 .

Urie, N. J., J. E. Lombard, C. B. Shivley, C. A. Kopral, A. E. Adams, T. J. Earleywine, J. D. Olson, and F. B. Garry. 2018. Preweaned heifer management on US dairy operations: Part I. Descriptive characteristics of preweaned heifer raising practices. J. Dairy Sci. 101:9168-9184. https://doi.org/10.3168/jds.2017-14010.

Valero, G., M. R. Alley, L. M. Badcoe, B. W. Manktelow, M. Merrall, and G. S. Lawes. 1990. Chondrodystrophy in calves associated with manganese deficiency. N. Z. Vet. J. 38:161-167. https://doi .org/10.1080/00480169.1990.35645.

Van Hoeck, V., J. L. Leroy, M. Arias Alvarez, D. Rizos, A. GutierrezAdan, K. Schnorbusch, P. E. Bols, H. J. Leese, and R. G. Sturmey 2013. Oocyte developmental failure in response to elevated nonesterified fatty acid concentrations: Mechanistic insights. Reproduction 145:33-44. https://doi.org/10.1530/REP-12-0174.

Van Hoeck, V., D. Rizos, A. Gutierrez-Adan, I. Pintelon, E. Jorssen, I. Dufort, M. A. Sirard, A. Verlaet, N. Hermans, P. E. Bols, and J. L. Leroy. 2015. Interaction between differential gene expression profile and phenotype in bovine blastocysts originating from oocytes exposed to elevated non-esterified fatty acid concentrations. Reprod. Fertil. Dev. 27:372-384. https://doi.org/10.1071/RD13263.

Van Saun, R. J. 2019. Interrelationships between maternal and fetal mineral status: A new perspective. In Proc. 52nd Annu. Conf. Am. Assoc. Bovine Pract. Am. Assoc. Bovine Pract., St. Louis, MO.

Windeyer, M. C., K. E. Leslie, S. M. Godden, D. C. Hodgins, K. D. Lissemore, and S. J. LeBlanc. 2014. Factors associated with morbidity, mortality, and growth of dairy heifer calves up to 3 months of age. Prev. Vet. Med. 113:231-240. https://doi.org/10.1016/j .prevetmed.2013.10.019.

Wu, G., F. W. Bazer, J. M. Wallace, and T. E. Spencer. 2006. Boardinvited review: Intrauterine growth retardation: Implications for the animal sciences. J. Anim. Sci. 84:2316-2337. https://doi.org/ 10.2527/jas.2006-156.

Zhou, Z., J. J. Loor, F. Piccioli-Cappelli, F. Librandi, G. E. Lobley, and E. Trevisi. 2016. Circulating amino acids in blood plasma during the peripartal period in dairy cows with different liver functionality index. J. Dairy Sci. 99:2257-2267. https://doi.org/ 10.3168/jds.2015-9805.

Ziech, D., R. Franco, A. Pappa, and M. I. Panayiotidis. 2011. Reactive oxygen species (ROS)-induced genetic and epigenetic alterations in human carcinogenesis. Mutat. Res. 711:167-173. https://doi .org/10.1016/j.mrfmmm.2011.02.015.

\section{ORCIDS}

Angel Abuelo @ https://orcid.org/0000-0001-9734-0148 